\title{
Mass-diameter regressions for moose browse on the Copper River Delta, Alaska
}

\author{
JAMES G. MacCRACKEN AND VICTOR VAN BALLENBERGHE
}

\begin{abstract}
Authors were graduate research assistant, Department of Fish and Wildlife Resources, University of Idaho, Moscow 83843; and research wildlife biologist, USDA, Forest Service, Pacific Northwest Research Station, Institute of Northern Forestry, 201 E. Ninth Ave., Suite 206, Anchorage, Alaska 99501. MacCracken is currently research scientist, Policy Analysis Group, College of Forestry, Wildlife, and Range Sciences, University of Idaho.
\end{abstract}

\begin{abstract}
Regression equations were developed to predict 3 mass components of 7 browse species important to moose (Alces alces gigas) on the Copper River Delta in southcentral Alaska. The accuracy of model predictions was the criterion for model selection. Model accuracy was evaluated using data splitting or jackknife procedures. Annual production of twigs and leaves and available twig mass on a stem were most accurately predicted from stem basal diameter with zero intercept models, zero intercept log-linear models, or log-log models. Twig mass eaten by moose was most accurately predicted from the diameter at the point of browsing of a twig with zero intercept or full linear models. Heteroskedasticity was significant $(P<0.05)$ in most of the data sets and could not be significantly reduced with $\log$ transformations or use of weighted least squares models. Heteroskedasticity appeared to have a relatively minor effect on model predictions. Most of the models gave mean predictions within $\pm 20 \%$ of the actual values, particularly for the most ubiquitous species that were also the most important to moose. For each species, there were few differences $(P<0.05)$ in model coefficients between years and among habitat types. Differences in coefficient estimates appeared to be related to differences in stem morphology that were related to both site conditions and past browsing by moose.
\end{abstract}

Key Words: Alaska, Alces alces, browse, Copper River Delta, mass estimates, moose, predictive regression equations

A common procedure to estimate the mass (i.e., weight/unit area) of browse (i.e., trees and shrubs) is to relate an easily measured attribute of a plant or plant part to its weight using regression equations (Shafer 1963, Peek et al. 1971, MacCracken and Viereck 1990). The objective is to predict plant mass from the measured attribute.

A variety of measurements have been used as the independent variable in regression equations. These include twig basal diameter (Telfer 1969, Ruyle et al. 1983, Roundy et al. 1989), twig diameter at the point of browsing (Telfer 1969, Peek et al. 1971, MacCracken and Viereck 1990), canopy area and volume (Peek 1970, Uresk et al. 1977, Yarie and Mead 1989), basal stem diameter (Brown 1976, Alaback 1986), and basal stem circumference and number of twigs/stem (Oldemeyer 1982).

Most investigators have used simple least squares linear regression models to predict browse mass components (Basile and Hutchings 1966, Lyon 1970, Ferguson and Mardsen 1977, Thilenius 1988). These models often contain significant negative intercept coefficients that could result in negative predictions. Negative

The USDA, Forest Service, Chugach National Forest, provided financial and logistical support. K.I. Giezentanner helped in many ways. A. Connors, C. Benson, and $T$. Levkovitz measured, clipped, and weighed samples for this study. J.L. Oldemeyer, J.M. Peek, and D.W. Uresk reviewed an earlier draft of the manuscript.

Manuscript accepted 10 Oct. 1992. intercepts may result from fitting a straight line to exponentially distributed data, or be a function of measurement imprecision and a limited sample for small $\mathrm{y}$ and $\mathrm{x}$ values, or a linear distribution that is truncated at a minimum threshold for both $y$ and $x$. Methods to deal with an exponential distribution are well known, but the latter cases have not been adequately addressed.

Heteroskedasticity, in the form of increasing variation with increasing values of the independent variable, is a common problem when relating plant mass to other characteristics (Baskerville 1972). Formal tests have been developed to determine whether heteroskedasticity is significant (Glejser 1969). Logarithmic data transformations and weighted least square models are often used to reduce heteroskedasticity (Koutsoyiannis 1977). Few authors have examined their data for heteroskedasticity (Oldemeyer 1982, Ruyle et al. 1983, Rumble 1987) and the effect of heteroskedasticity on the predictive ability of regression equations is not well documented.

Many researchers have found that regression equations differ among species of browse (Telfer 1969, Peek 1970, Alaback 1986). In addition, equation coefficients may differ for a species among sampling sites (Peek et al. 1971, Ruyle et al. 1983, Roundy et al. 1989), with the size of the plant (Lyon 1970), by vegetation type (Yarie and Mead 1989), and with twig location on a plant (Basile and Hutchings 1966). Some authors suggested that small, statistically significant differences in equation coefficients had no practical implications (Basile and Hutchings 1966, Lyon 1970), while others stated that separate equations may need to be developed (Peek et al. 1971, Ruyle et al. 1983). What effect differences in coefficients for the same species have on the predictive ability of regression equations has not been objectively evaluated.

Few studies have formally evaluated the accuracy of regression models when used to predict plant mass (Thilenius 1988, 1990, Yarie and Mead 1989). A large $r^{2}$ (Brown 1976, Ruyle et al. 1983), small standard errors of coefficient estimates (Roundy et al. 1983), or decreased variance in mass estimates (Uresk et al. 1977) are not accurate indicators of predictive ability. In studies where regressions were used to estimate browse use it has been common to compare use estimates between regression techniques and other methods (Ferguson and Mardsen 1977, Provenza and Urness 1981, Ruyle et al. 1983). These are not tests of a models predictive ability either.

Snee (1977) discussed 4 methods for validating regression models. Two were based on theoretical expectations and 2 were databased. The 2 data-based methods were the collection of new data and a data splitting or cross-validation approach. Jackknife and bootstrap resampling techniques (Krebs 1989) can also be used to generate model validation data sets. However, there is currently no formal method that we know of to objectively compare $y$ and $\hat{y}$ of validation data sets. 
The objectives of this study were to develop regression equations to predict the current annual growth of twigs and leaves (annual production), over-winter available mass, and mass eaten for browse used by moose on the Copper River Delta, Alaska. Our goal was to use 1 equation/mass component/species. We also assessed the predictive ability of the equations and examined the effects of yearly variation and habitat type on equation coefficient estimates.

\section{Study Area and Methods}

The Copper River Delta is located in coastal southcentral Alaska and is the largest contiguous wetland $\left(\approx 3,000 \mathrm{~km}^{2}\right)$ remaining on the Pacific coast of North America. The study area was described in detail by MacCracken (1992). Wetland herbaceous and shrub-dominated plant communities are abundant in lowland areas, with drier upland sites occupied by tall shrub communities, spruce [Picea sitchensis (Bong.) Carr.], or cottonwood (Populus trichocarpa Torr. \& Gray) forest.

Preliminary results indicated that 4 browse-dominated habitat types (plant communities) were used the most by moose and that the study area could be divided into 5 sections unique in physiographic features, climate, vegetation development, and use by moose (MacCracken 1992). In each of those 5 sections, 4 permanent sampling sites $(0.25 \mathrm{ha})$ were established representing each of the 4 habitat types used by moose. Habitat type classification followed Viereck et al. (1986).

Samples used to estimate regression equations to predict annual production of twigs and leaves and available mass of 7 browse species were collected at each site twice during 1988 and 1989. Sites were sampled in mid-April to mid-May, prior to leaf flush and during July-August, at peak mass. At each site, 5-10 individual stems of each browse species were harvested after the basal diameter was measured. A stem was a single shoot originating below the soil/moss/litter surface and the basal diameter was measured $(\mathrm{mm})$ above the soil/moss/ litter surface and the root crown. Stems were selected for sampling with a stratified random design, insuring that the full range of basal diameters for each species at a site was sampled. The strata were $10-\mathrm{mm}$ basal diameter classes and the number of strata and stems sampled/strata varied with site characteristics. Harvested stems were separated into mass components in the lab, dried for 48 hours at $60^{\circ} \mathrm{C}$, and weighed to the nearest 0.1 g.

For over-winter available mass estimates, twigs had 2 components: current annual growth and older portions (Telfer 1969). The limit of a twig was defined as the maximum diameter at the point of browsing (DPB) measured at a site for each species. If a species had not been browsed at a site, the average maximum diameter at the point of browsing of all other sites was used to define a twig.

Samples for developing regression equations to predict twig mass eaten were collected during October-December 1988 from 6 of the permanent sampling sites. All 4 habitat types were sampled plus an additional site in each of the 2 most important foraging habitats. At each site, up to 10 twigs were randomly clipped from 10 different stems for each species. Some stems had evidence of past browsing, but none had been recently browsed. Clipped twigs included all current annual growth and older material to insure that the full range of diameters at the point of browsing were sampled. In the lab, the twigs were clipped at 1-3 points along their length. The diameter at the point of clipping (= DPB) was measured with a pair of calipers to the nearest $0.1 \mathrm{~mm}$. The samples were oven-dried for 48 hours at $60^{\circ} \mathrm{C}$ then weighed to the nearest $0.1 \mathrm{~g}$. Twig mass posterior to the point of clipping $(\mathrm{y})$ was related to the diameter at the point of browsing $(x)$.

Data plots were examined to estimate the form (linear, curvilinear, exponential, etc.) of the mass-diameter relationships. If the plots indicated that nonlinear relationships existed, appropriate data transformations were applied and linear models were estimated with ordinary least squares regression.

The predictive ability of most of the equations was evaluated using the data splitting method (Snee 1977). Prior to the development of the models, $10 \%$ of each data set was set aside as a validation data set $\left(y_{v}, x_{v}\right)$. Observations for the validation data set were chosen with a stratified random sampling procedure to insure that all year and habitat type categories were represented. Sample sizes for feltleaf willow [Salix alaxensis (Anderss.) Cov.] and cottonwood were too small to generate adequate validation data sets by splitting the data. For these species, jackknife procedures were used to validate the models (Krebs 1989). Comparisons between $y_{v}$ and $\hat{y}_{v}$ were made by calculating the mean of each and determining the percent deviation (Thilenius 1988). Retransformation bias was corrected for log-log models (Baskerville 1972, Sprugle 1982). The models that resulted in the smallest deviation between the means of $y_{v}$ and $\hat{y}_{v}$ were the models of choice. In addition, minimum root mean square error and maximum $r^{2}$ were also used as criteria to choose the best model. However, if these 3 criteria conflicted, prediction accuracy had priority.

Most statistical packages report an $r^{2}$ statistic that is appropriate only for full linear models (Kvalseth 1985). We report that $R_{1^{2}}$ $\left(1-[y-\hat{y}]^{2} /(y-\bar{y}]^{2}\right)$ of Kvalseth (1985) when models other than full linear models were estimated.

Once the best model was obtained, residual plots were examined to decide if testing for heteroskedasticity was warranted. Procedures outlined by Glejser (1969) were used to test if heteroskedasticity was significant. If it was, a weighted least squares model was estimated and tested to determine if heteroskedasticity had been significantly reduced (Koutsoyiannis 1977).

The effect of habitat type and year on equation coefficient estimates was examined by restructuring the data matrix using dummy variables so that 1 equation contained coefficients for each variable of interest. Comparisons of both intercept and slope coefficients between years and 2 habitat types were done with $t$-tests. Comparisons involving $>2$ habitats were made with F-tests, followed by all pairwise comparisons to determine which habitat produced a significant F (Koutsoyiannis 1977). Statistical significance was accepted at $P \leq 0.05$.

Table 1. Sample sizes for developing and testing regression equations to predict browse mass components on the Copper River Delta, Alaska.

\begin{tabular}{|c|c|c|c|c|c|}
\hline \multirow[b]{3}{*}{ Species } & \multicolumn{5}{|c|}{ Production and available mass } \\
\hline & \multicolumn{2}{|c|}{ Spring } & \multicolumn{2}{|c|}{ Summer } & \multirow{2}{*}{$\begin{array}{l}\text { Validation } \\
\text { sample }\end{array}$} \\
\hline & 1988 & 1989 & 1988 & 1989 & \\
\hline & \multicolumn{5}{|c|}{$\ldots \ldots$ (Number of stems sampled) $\ldots \ldots$} \\
\hline Alnus sinuata & 108 & 129 & 104 & 92 & 43 \\
\hline Myrica gale & 70 & 70 & 70 & 70 & 23 \\
\hline Populus trichocarpa & 16 & 31 & 12 & 30 & $*$ \\
\hline Salix alaxensis & 20 & 20 & 20 & 20 & $*$ \\
\hline S. barclayi & 127 & 169 & 127 & 112 & 60 \\
\hline S. commutata & 29 & 39 & 49 & 40 & 10 \\
\hline \multirow[t]{3}{*}{ S. sitchensis } & 66 & 110 & 88 & 81 & 37 \\
\hline & \multicolumn{5}{|c|}{ Mass eaten } \\
\hline & & total & \multicolumn{3}{|c|}{ validation sample } \\
\hline & \multicolumn{5}{|c|}{$\ldots \ldots(\overline{\text { Number of twigs sampled }) \ldots . .}$} \\
\hline A. sinuata & & 110 & & 21 & \\
\hline M. gale & & 126 & & 13 & \\
\hline P. trichocarpa & & 53 & & 10 & \\
\hline S. alaxensis & & 84 & & 10 & \\
\hline S. barclayi & & 155 & & 21 & \\
\hline S. sitchensis & & 141 & & 16 & \\
\hline
\end{tabular}

*models validated with the jackknife procedure. 


\section{Browse Production and Availability}

The number of stems sampled to estimate equations to predict production and available mass ranged from $80-535$ (Table 1). For each species, all mass-basal diameter relationships were either linear or $\log$ transformed. Significant $(P<0.05)$ equations were obtained for each species-mass component with $r^{2}$ ranging from 0.16-0.76 (Table 2). Linear or log-linear models resulted in the most accurate predictions for $85 \%$ of the data sets. Log-log models were most appropriate for the remaining $15 \%$. However, full linear and log-linear models had negative intercepts resulting in negative predictions. Zero intercept linear and log-linear models were used for the data sets in which log-log models were inappropriate.

Eighty-five percent of the models overestimated browse mass components (Table 2). Deviation of the means of $y_{v}$, and $\hat{y}_{v}$ ranged from $-9 \%$ to $35 \%$. Seventy-three percent of the equations gave mean predictions within $\pm 20 \%$ of the actual values. The predictive

Table 2. Mass-diameter regressions for browse used by moose on the Copper River Delta, Alaska. Equations estimate annual production of twigs and leaves, available mass, and mass eaten by moose/twig browsed during winter.

\begin{tabular}{|c|c|c|c|c|c|}
\hline \multirow{2}{*}{\multicolumn{2}{|c|}{ Species-mass component models }} & \multirow[b]{2}{*}{$r^{2 *}$} & \multicolumn{3}{|c|}{ Model validation } \\
\hline & & & $y_{v}(S E)$ & $\hat{y}_{\mathrm{y}}(\mathrm{SE})$ & $\%$ Deviation! \\
\hline \multicolumn{6}{|c|}{$\begin{array}{l}\text { Annual production and available mass } \\
\text { Alnus sinuata }\end{array}$} \\
\hline twig (winter) & $=1.21(\mathrm{BD})$ & 0.42 & $27.0(12.5)$ & $30.3(5.8)$ & 11 \\
\hline available mass (winter) & $=2.33(\mathrm{BD})$ & 0.49 & $58.4(27.2)$ & $58.3(11.2)$ & -1 \\
\hline twig (summer) & $=-3.97\left(\mathrm{BD}^{1.77}\right)^{2}$ & 0.76 & $6.1(1.6)$ & $5.0(0.3)$ & -19 \\
\hline leaf & $=4.53(\mathrm{BD})$ & 0.63 & $37.8(11.8)$ & $86.7(16.3)$ & 56 \\
\hline total (leaf+twig CAG) & $=5.14(\mathrm{BD})$ & 0.63 & $43.9(13.0)$ & $98.3(18.5)$ & 55 \\
\hline \multicolumn{6}{|l|}{ Myrica gale } \\
\hline twig (winter \& summer) & $=1.20(\mathrm{BD})$ & 0.16 & $2.5(0.5)$ & $2.5(0.1)$ & 0 \\
\hline available mass (winter) & $=-3.33\left(\mathrm{BD}^{2.15}\right)$ & 0.61 & $5.1(0.7)$ & $4.9(0.2)$ & -4 \\
\hline leaf & $=3.65(\mathrm{BD})$ & 0.36 & $6.8(1.7)$ & $7.4(0.8)$ & 8 \\
\hline total (leaf +twig CAG) & $=4.52(\mathrm{BD})$ & 0.36 & $9.3(2.2)$ & $9.1(1.0)$ & -2 \\
\hline \multicolumn{6}{|l|}{ Populus trichocarpa } \\
\hline twig (winter) & $=1.33(\mathrm{BD})$ & 0.72 & $33.3(6.2)$ & $38.4(4.1)$ & 13 \\
\hline available mass (winter) & $=2.37(\mathrm{BD})$ & 0.58 & $56.5(12.8)$ & $71.0(7.2)$ & 20 \\
\hline twig (summer) & $=0.98(\mathrm{BD})$ & 0.75 & $16.5(5.0)$ & $22.8(3.2)$ & 28 \\
\hline leaf & $=4.82(\mathrm{BD})$ & 0.69 & $73.4(26.6)$ & $111.4(15.3)$ & 34 \\
\hline total (leaf+twig CAG) & $=5.79(\mathrm{BD})$ & 0.70 & $90.0(31.5)$ & $134.4(18.5)$ & 33 \\
\hline \multicolumn{6}{|l|}{ Salix alaxensis } \\
\hline twig (winter) & $=0.42(\mathrm{BD})$ & 0.38 & $6.7(1.3)$ & $7.0(0.7)$ & 4 \\
\hline available mass (winter) & $=1.00(\mathrm{BD})$ & 0.54 & $13.4(3.2)$ & $15.4(1.5)$ & 13 \\
\hline twig (summer) & $=0.51(\mathrm{BD})$ & 0.64 & $11.4(2.7)$ & $12.5(2.2)$ & 19 \\
\hline leaf & $=2.52(\mathrm{BD})$ & 0.55 & $50.4(15.7)$ & $62.3(11.3)$ & 19 \\
\hline total (leaf+twig CAG) & $=3.03(\mathrm{BD})$ & 0.57 & $61.8(22.8)$ & $75.1(13.4)$ & 18 \\
\hline \multicolumn{6}{|l|}{ S. barclayi } \\
\hline twig (winter \& summer) & $=0.36(\mathrm{BD})$ & 0.62 & $7.4(0.8)$ & $7.7(1.0)$ & 4 \\
\hline available mass (winter) & $=1.51(\mathrm{BD})$ & 0.44 & $34.7(7.8)$ & $33.5(5.6)$ & -4 \\
\hline leaf & $=1.43(\mathrm{BD})$ & 0.52 & $26.1(6.0)$ & $29.5(3.6)$ & 12 \\
\hline total (leaf+twig) CAG) & $=1.76(\mathrm{BD})$ & 0.52 & $32.6(7.6)$ & $36.3(4.4)$ & 10 \\
\hline \multicolumn{6}{|l|}{ S. commutata } \\
\hline twig (winter) & $=-4.39\left(\mathrm{BD}^{1.92}\right)$ & 0.65 & $5.1(2.3)$ & $5.2(0.4)$ & 2 \\
\hline available mass (winter) & $=0.55(\mathrm{BD})$ & 0.48 & $8.6(2.7)$ & $8.7(1.5)$ & 1 \\
\hline twig (summer) & $=0.16(\mathrm{BD})$ & 0.37 & $1.7(0.6)$ & $1.9(0.3)$ & 11 \\
\hline leaf & $=0.94(\mathrm{BD})$ & 0.50 & $10.3(3.3)$ & $11.2(1.6)$ & 8 \\
\hline total (leaf+twig CAG) & $=1.10(\mathrm{BD})$ & 0.49 & $12.0(3.9)$ & $13.1(1.9)$ & 8 \\
\hline \multicolumn{6}{|l|}{ S. sitchensis } \\
\hline twig (winter) & $=-3.74\left(\mathrm{BD}^{1.77}\right)$ & 0.34 & $4.8(1.4)$ & $5.2(0.3)$ & 8 \\
\hline available mass (winter) & $=11.07(\ln B D)$ & 0.20 & $21.0(7.1)$ & $30.4(5.6)$ & 31 \\
\hline twig (summer) & $=-5.29\left(\mathrm{BD}^{2.35}\right)$ & 0.56 & $6.6(1.6)$ & $6.7(0.3)$ & 1 \\
\hline leaf & $=10.69(\operatorname{lnBD})$ & 0.28 & $24.2(5.7)$ & $30.6(1.5)$ & 21 \\
\hline total (leaf+twig CAG) & $=13.04(\ln \mathrm{BD})$ & 0.28 & $30.7(7.1)$ & $37.3(1.8)$ & 18 \\
\hline \multicolumn{6}{|l|}{ Mass eaten regressions } \\
\hline Alnus sinuata & $=0.34\left(\mathrm{DPB}^{4}\right)$ & 0.67 & $1.7(0.4)$ & $1.7(0.4)$ & $\mathbf{0}$ \\
\hline Myrica gale & $=0.12\left(\mathrm{DPB}^{2}\right)$ & 0.79 & $0.7(0.3)$ & $0.7(0.3)$ & 0 \\
\hline Populus trichocarpa & $=0.04\left(\mathrm{DPB}^{2.6}\right)$ & 0.92 & $1.2(0.5)$ & $1.8(0.6)$ & 33 \\
\hline Sallx alaxensis & $=0.08+0.01\left(\mathrm{DPB}^{3.4}\right)$ & 0.95 & $1.9(0.7)$ & $2.0(0.8)$ & 5 \\
\hline S. barclayi & $=0.05+0.03\left(\mathrm{DPB}^{2.7}\right)$ & 0.81 & $1.1(0.4)$ & $1.2(0.4)$ & 8 \\
\hline S. sitchensis & $=0.03+0.06\left(\mathrm{DPB}^{2.5}\right)$ & 0.80 & $1.4(0.6)$ & $1.4(0.5)$ & 0 \\
\hline
\end{tabular}

$\left.1\left(\left[\hat{\mathrm{y}}_{\mathrm{v}}-\mathrm{y}_{\mathrm{v}}\right]\right) / \hat{\mathrm{y}}_{\mathrm{v}}\right) 100$.

analyzed as $\ln y=b_{0}+b_{1}(\ln x)$.

* see Methods for calculation for zero intercept and log-log models.

1.. or $\mathrm{g} \mathbf{t} / \mathbf{t w i g}$. 


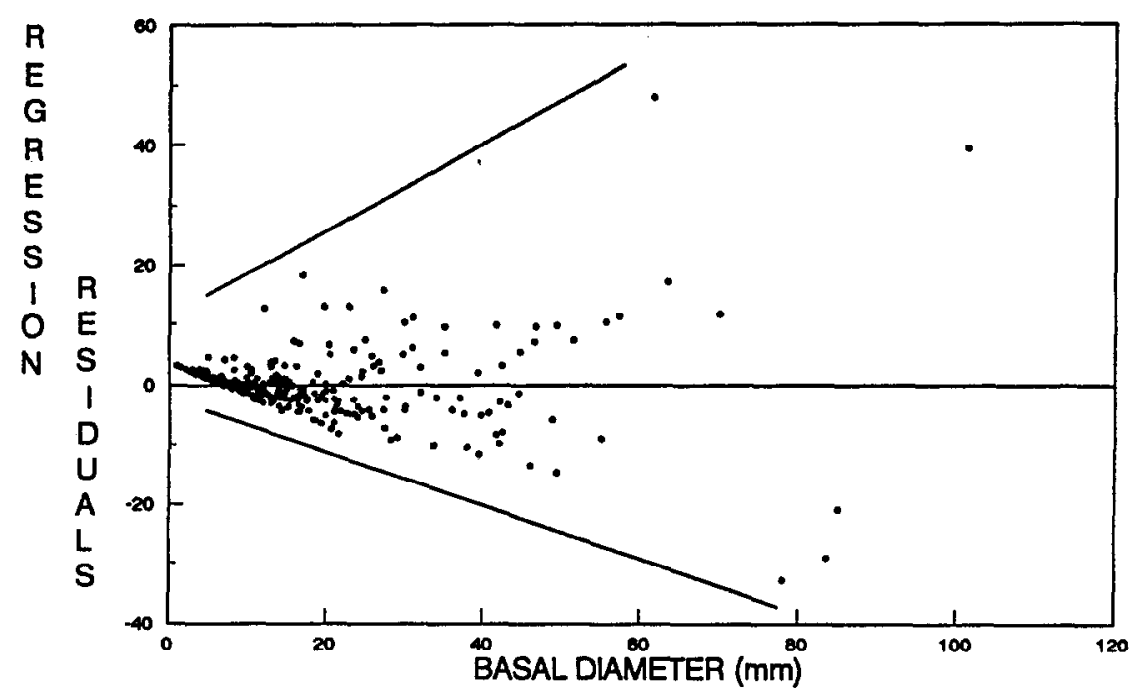

Fig. 1. A plot of residuals against the independent variable from the regression of current growth twig mass on stem basal diameter for Barclay willow. The funnel shaped distribution of the residuals suggested that heteroskedasticity in the data was a problem. The significance of heteroskedasticity was tested using procedures suggested by Glejser (1969).

ability of the models was not related to their $r^{2}$ value $\left(r_{\mathrm{s}}=0.19\right.$, $P>0.05$ ).

Heteroskedasticity was significant $(P<0.05)$ in $77 \%$ of the massbasal diameter data sets, taking the form of increasing variance with increasing basal diameter (Fig. 1). Weighted least squares or log transformations did not significantly reduce heteroskedasticity in any data set and were not used.

Differences $(P<0.05)$ between years and habitat types in equation coefficients occurred in only $39 \%$ and $37 \%$ of all comparisons, respectively (Table 3 ). A majority of those differences were for the basal diameter coefficient. Significant differences $(P<0.05)$ for equation coefficients among habitat types occurred most often when contrasting habitats used by moose for foraging with those used for bedding.

\section{Mass Eaten}

The number of twigs sampled to estimate the mass of browse eaten by moose ranged from 53-155 (Table 1). Only 6 species were sampled since there was no evidence of moose eating undergreen willow ( $S$. commutata Bebb). All mass-diameter at the point of browsing relationships were linear, but diameter at the point of browsing raised to a power resulted in the most accurate predictions with $r^{2}$ ranging from $0.67-0.92$ (Table 2). Each model was significant $(P<0.001)$, and zero intercept models were used for 2 species. Of the 4 models with a positive intercept, only 1 was significantly different from zero $(P<0.05)$ (Table 2$)$.

Fifty percent of the predictions were overestimates (Table 2). The mean deviation ranged from $0 \%-33 \%$, and was greatest for cottonwood. The predictive ability of these models was weakly related to their $r^{2}$ value $\left(\mathrm{r}_{\mathrm{a}}=0.76, P=0.05\right)$.

Heteroskedasticity was significant $(P<0.05)$ for each species, taking the form of increasing variance with increasing diameter at the point of browsing. Log transformations and weighted least squares models did not significantly reduce heteroskedasticity and were not used.

Differences $(P<0.05)$ in equation coefficients among habitat types occurred in 55\% of all possible comparisons (Table 4). Sixty percent of those differences were due to the diameter at the point of browsing coefficient. Seventy percent of the habitat type differences were associated with comparisons of habitats used by moose for foraging vs. bedding.

\section{Discussion}

Numerous investigators have used regression equations to predict browse mass, but few have attempted to evaluate the accuracy of those predictions (Thilenius 1988, 1990; Yarie and Mead 1989). The lack of a formal summary statistic to compare $y_{v}$ and $\hat{y}_{v}$ makes models validation difficult and subjective. The $\chi^{2}$ goodness-of-fit test is appropriate only for categorical data. Furthermore, most statistical methods that could be applied (e.g., $t$-test) test the hypothesis that a function of a parameter of the 2 data sets is not different from zero, not each other (e.g., $\overline{\mathbf{x}}_{1}-\overline{\mathbf{x}}_{2}=0$ ).

Linear models resulted in the most accurate predictions for most of the mass-diameter relationships we examined. However, full linear models often contained significant negative intercepts, resulting in negative predictions for small diameters. In these situations, log-log models accurately represented only the lower portion of the data distribution and the predictions of those models were consistently poor due to large variation in the data at the upper end of the distribution (Fig. 2). The magnitude of prediction errors for large values accounted for the overall poor performance of $\log -\log$ models. These results suggest that a minimum threshold in massdiameter relationships may be the primary cause of negative intercepts in linear relationships.

We used zero intercept models when linear equations resulted in negative intercepts and $\log$-log models resulted in poor predictions. Zero intercept models are theoretically justified since zero mass occurs at zero diameter. In addition, minimum threshold linear relationships provide a data-based justification. Furthermore, we found that zero intercept models either improved or did not alter the accuracy of mass predictions in $64 \%$ of the data sets in which a full linear or log-linear model was appropriate. We conclude that zero intercept models adequately solved the problems associated with data sets that were essentially linear, but truncated at a minimum threshold. Yarie and Mead (1989) also used zero intercept models and reported predictions of $-11,-40$, and $-55 \%$ of mass estimates derived from plot clipping methods.

Thilenius $(1988,1990)$ reported a deviation of $<1 \%$ between predicted and actual mass of current annual growth twigs of Barclay willow ( $S$. barclayi Anderss.) on the Copper River Delta. Our predictions were a $4 \%$ overestimate. Differences between predictions of twig current annual growth from actual values for sweetgale (Myrica gale L.) reported by Thilenius (1990) ranged from 
Table 3. Significant differences in regression equation coefficients between years and among habitat types for browse used by moose on the Copper River Delta, Alaska. For year comparisons, positive $t$ statistics indicate that $1988>1989$, and vice-versa.

\begin{tabular}{|c|c|c|c|c|}
\hline \multirow{2}{*}{$\begin{array}{l}\text { Species and } \\
\text { mass component }\end{array}$} & \multicolumn{2}{|c|}{ Year } & \multicolumn{2}{|c|}{ Habitat type } \\
\hline & $\mathrm{b}_{0}$ & $b_{1}$ & $\mathbf{b}_{0}$ & $b_{1}$ \\
\hline $\begin{array}{l}\text { Alnus sinuata } \\
\text { twig (winter) } \\
\text { available mass } \\
\text { twig (summer) } \\
\text { leaf } \\
\text { total }\end{array}$ & NSD & $\begin{array}{c}t=3.69^{* * *} \\
\text { NSD } \\
\text { NSD } \\
\text { NSD } \\
\text { NSD }\end{array}$ & NSD & $\begin{array}{l}\text { NSD } \\
\text { NSD } \\
\text { NSD } \\
\text { NSD }\end{array}$ \\
\hline $\begin{array}{l}\text { Myrica gale } \\
\text { twig (winter-summer) } \\
\text { available mass } \\
\text { leaf } \\
\text { total }\end{array}$ & NSD & $\begin{aligned} & \text { NSD } \\
& \text { NSD } \\
t= & 3.17^{* * *} \\
t= & 2.81^{* *}\end{aligned}$ & NSD & $\begin{array}{l}\text { NSD } \\
\text { NSD } \\
\text { NSD } \\
\text { NSD }\end{array}$ \\
\hline $\begin{array}{l}\text { Populus trichocarpa } \\
\text { twig (winter-summer) } \\
\text { available mass } \\
\text { twig (summer) } \\
\text { leaf } \\
\text { total }\end{array}$ & & $\begin{array}{l}t=-3.53^{* * *} \\
t=-3.19^{* * *} \\
t=-3.01^{* * *} \\
t=-2.79^{* *} \\
t=-2.92^{* *}\end{array}$ & & $\begin{array}{c}\text { NSD } \\
t=4.14^{* * * *} \\
\text { OAW>CAW } \\
\text { NSD } \\
\text { NSD } \\
\text { NSD }\end{array}$ \\
\hline $\begin{array}{r}\text { Salix alaxensis } \\
\text { twig (winter) }\end{array}$ & & NSD & & $\begin{array}{c}t=2.90^{* *} \\
\mathrm{CAW}>0 \mathrm{AW}\end{array}$ \\
\hline $\begin{array}{l}\text { available mass } \\
\text { twig (summer) }\end{array}$ & & $\begin{aligned} & t= 2.10^{*} \\
& \text { NSD }\end{aligned}$ & & $\begin{array}{c}\text { NSD } \\
t=6.17^{* * *} \\
\text { CAW }>0 A W\end{array}$ \\
\hline $\begin{array}{l}\text { leaf } \\
\text { total }\end{array}$ & & $\begin{array}{l}t=-2.63^{* *} \\
t=-2.46^{* *}\end{array}$ & & $\begin{array}{c}t=4.90^{* * *} \\
\text { CAW>OAW } \\
t=5.08^{* * *} \\
\text { CAW>OAW }\end{array}$ \\
\hline $\begin{array}{l}\text { S. barclayi } \\
\text { twig (winter-summer) }\end{array}$ & & NSD & & $\begin{array}{c}F=15.0^{* * *} \\
\text { CAW>MS; } \\
\text { CAW, OAW } \\
M S>W S\end{array}$ \\
\hline $\begin{array}{l}\text { available mass } \\
\text { leaf } \\
\text { total }\end{array}$ & & $\begin{array}{l}\text { NSD } \\
\text { NSD } \\
\text { NSD }\end{array}$ & & $\begin{array}{c}\text { NSD } \\
F=3.7^{*} \\
\text { CAW, } \text { OAW }>M S \\
\text { NSD }\end{array}$ \\
\hline $\begin{array}{l}\text { S. commutata } \\
\text { twig (winter) } \\
\text { available mass } \\
\text { twig (summer) } \\
\text { total }\end{array}$ & NSD & $\begin{aligned} & t=2.79^{*} \\
& t=-4.50^{* * *} \\
& t= 3.50^{* * *} \\
& \text { NSD }\end{aligned}$ & $F=18.6^{* * *}$ & $\begin{array}{l}\text { NSD } \\
t=-3.59^{* * *} \\
\text { WS }>\text { MS } \\
t=-2.00^{*} \\
\text { WS }>\text { MS } \\
\text { NSD }\end{array}$ \\
\hline $\begin{array}{l}\text { S. sitchensis } \\
\text { twig (winter) } \\
\text { available mass } \\
\text { twig (summer) } \\
\text { leaf } \\
\text { total }\end{array}$ & NSD & $\begin{array}{l}\text { NSD } \\
\text { NSD } \\
\text { NSD }\end{array}$ & $\begin{array}{c}F=5.6^{* *} \\
\text { OAW, CAW>MS }\end{array}$ & $\begin{array}{c}\text { NSD } \\
F=41.5^{* * *} \\
\text { CAW, OAW }>\text { MS } \\
\text { NSD } \\
\text { NSD } \\
\text { NSD }\end{array}$ \\
\hline
\end{tabular}

${ }^{1} \mathrm{CAW}=$ closed alder-willow, $\mathrm{OAW}=$ open alder-willow, $\mathrm{MS}=$ sweetgale-willow, and $\mathrm{WS}=$ woodland spruce babitat types.

${ }^{2} \mathrm{NSD}=$ no significant difference $(P>0.05)$

$*=P<0.05,{ }^{* *}=P<0.01,{ }^{* * *}=P<0.001$.

$-42 \%$ to $16 \%$. When averaged, our predictions were equal to the actual values. Thilenius $(1988,1990)$ collected Barclay willow and sweetgale samples from 2 adjacent sites, in 1 habitat type. In contrast, we sampled all habitat types where these species occurred with a replicated sampling scheme. Our equations should have broader application and greater accuracy in a variety of habitat types.
Raising diameter at the point of browsing to the power indicated (Table 2) is justified by the fact that twig mass is closely related to twig volume. Volume is a 3-dimensional measure and for most species, diameter at the point of browsing raised to a power very close to the volumetric expectation of 3 resulted in the most accurate predictions. Only Sitka alder [Alnus sinuata (Reg.) Rydb.] deviated from this trend, presumably due to the fact that alder 


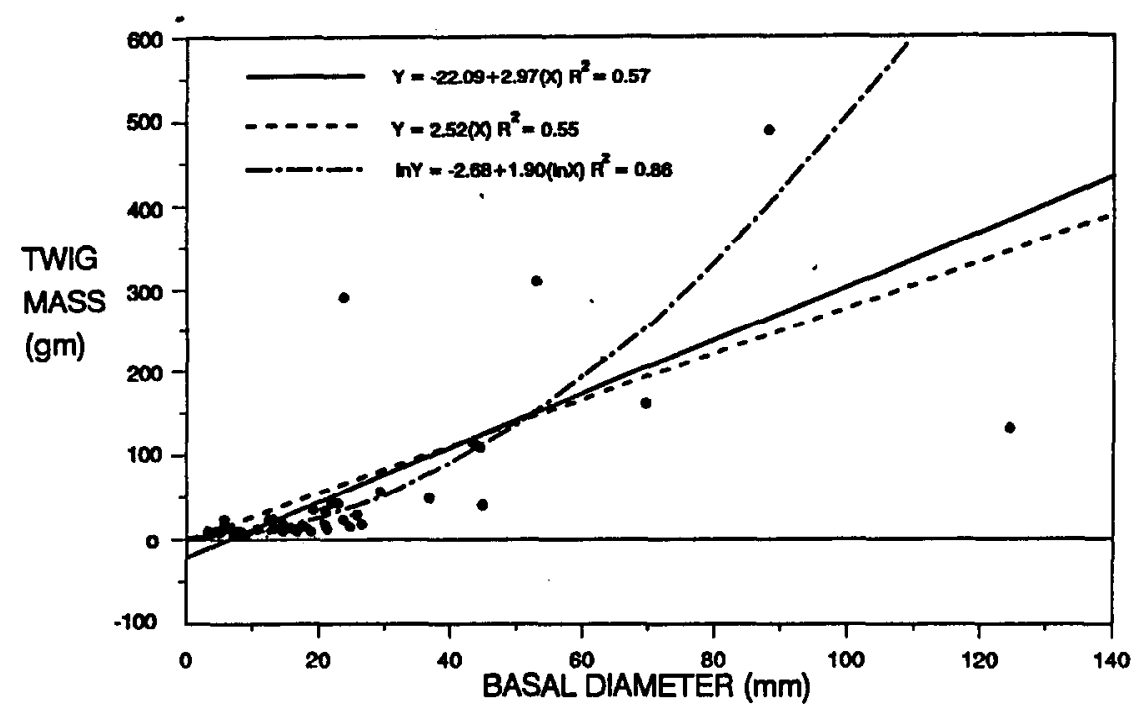

Fig. 2. A plot of 3 regression models fit to data for leaf mass $(y)$ and stem basal diameter $(x)$ for feltleaf willow. The full linear model produced a significant $(P<0.05)$ negative intercept, resulting in negative predictions for basal diameters $\leq 7.4 \mathrm{~mm}$ and a deviation of $6 \%$ between $\mathbf{y}_{v}$ and $\hat{y}_{v}$. The log-log model resulted in a deviation of $-48 \%$ between $y_{v}$ and $\hat{y}_{v}$ despite the high $r^{2}$. The zero intercept model resulted in $a$ deviation of $20 \%$ between $y_{v}$ and $\hat{y}_{v}$. This example was typical for a majority of the mass-diameter relationships examined in this study.

Table 4. Significant differences in regression equation coefficients among habitat types for equations that predicted browse mass eaten by moose on the Copper River Delta, Alaska.

\begin{tabular}{lcc}
\hline & \multicolumn{2}{c}{ Equation coefficient } \\
\cline { 2 - 3 } Species & $\mathrm{b}_{0}$ & $\mathrm{~b}_{1}$ \\
\hline Alnus sinuata & $\mathrm{NSD}$ & $\mathrm{NSD}$ \\
Myrica gale & & $t=-5.00^{*}$ \\
& & WS $>\mathrm{MS}^{2}$ \\
Populus trichocarpa & $\mathrm{NSD}$ & $\mathrm{NSD}$ \\
Salix alaxensis & $F=6.60^{*}$ & $\mathrm{NSD}$ \\
S. barclayi & $\mathrm{CAW}, \mathrm{WS}, \mathrm{OAW}>\mathrm{MS} ;$ & MS $>$ WS; OAW $>$ OAS \\
& WS $>$ CAW & $F=106.8^{*}$ \\
S. sitchensis & $F=204.4^{*}$ & WS $>$ CAW, OAW \\
& WS $>$ OAW &
\end{tabular}

NSD $=$ no significant difference.

2CAW = closed alder-willow, $\mathrm{OAW}=$ open alder-willow, $\mathrm{MS}=$ sweetgalc-willow, and WS $=$ woodland spruce habitat types.

$=P<0.001$.

twigs were oblong in circumference, and the other species were round.

We identified a number of factors that could influence equation predictions. Heteroskedasticity was significant in most of the data sets we analyzed. Heteroskedasticity results in inefficient estimates of the model coefficients and biased standard errors and test statistics (Koutsoyiannis 1977). Our analysis produced variable results: some models with significant heteroskedasticity gave accurate predictions and others not. None of equations in which heteroskedasticity was insignificant $(P>0.05)$ resulted in predictions that deviated by more than $16 \%$ from the actual values. The predictions of $\log$-log models were influenced the greatest by heteroskedasticity. The effects of heteroskedasticity on linear model predictions appear to be minimal as suggested by Rumble (1987), but more formal testing is needed. The failure of the data transformations to significantly reduce heteroskedasticity suggests that it may be related to some variable other than basal diameter or diameter at the point of browsing. The fact that variation was relatively large at large diameters at the point of browsing and large basal diameters suggests that stem or twig age may be important.
Differences in equation coefficients for a species between years and among habitats were significant in some instances, suggesting that the goal of using 1 equation to predict browse mass components may be unrealistic. Those differences could influence the predictive ability of an equation when these data subsets are pooled. Even though some coefficients differences were large, model predictions did not suffer substantially when the data were pooled and 1 equation was used for prediction, particularly for the most ubiquitous species that were also the most important to moose (MacCracken 1992). Presumably, predictions would be improved if separate equations were estimated for each different factor. Our data sets were not large enough to adequately assess the predictive ability of equations for each habitat type occupied by a species. Furthermore, such a procedure may be beyond the ability of most projects due to time and budget constraints.

Differences in equations among habitat types are likely due to differences in stem or twig morphology that reflect varying environmental conditions or use by herbivores (Peek et al. 1971). A majority of the differences in equations occurred when contrasting habitats used by moose for foraging with those used primarily for bedding. This suggests that browsing significantly altered shrub morphology and mass distribution on a twig or stem; a fact that was apparent in the field and discussed by Oldemeyer (1982:55). However, shrub morphology also varied with the physical environment of a specific site, independent of moose foraging. In fact, plant morphology influenced the ability of moose to forage on specific stems. In closed alder-willow stands, Barclay willow (the most abundant and important species) had large stem diameters and were about 3-5 $\mathrm{m}$ tall; characteristics that inhibited foraging by moose.

The use of predictive regression equations outside of the time frame or area from which the equations were developed should be undertaken with caution. If predictive regressions are used in this manner, validation samples should be collected in order to check the accuracy of the predictions. Furthermore, this information could be used to correct any consistent bias that may be present in the predictions. 


\section{Literature Cited}

Alaback, P.B. 1986. Biomass regression equations for understory plants in coastal Alaska: effects of species and sampling design on estimates. Northwest Sci. 60:90-103.

Basile, J.V., and S.S. Hutchings. 1966. Twig diameter-length-weight relations of bitterbrush. J. Range Manage. 19:34-38.

Baskerville, G.L. 1972. Use of logarithmic regression in estimating plant biomass. Can. J. Forest. Res. 2:49-53.

Brown, J.K. 1976. Estimating shrub biomass from basal stem diameters. Can. J. Forest Res. 6:154-158.

Ferguson, R.B., and M.A. Marsden. 1977. Estimating overwinter bitterbrush utilization from twig diameter-length-weight relations. J. Range Manage. 30:231-236.

Glejser, H. 1969. A new test for heteroskedasticity. J. Amer. Stat. Assoc. 64:316-323.

Krebs, C.J. 1989. Ecological methodology. Harper and Row Publ., N.Y.

Koutsoyiannis, A. 1977. Theory of econometrics: an introductory exploration of econometric methods. Barnes and Noble Publ., N.Y.

Kvalseth, T.0. 1985. Cautionary note about $\mathbf{R}^{2}$. Amer. Stat. 39:279-285

Lyon, L.J. 1970. Length- and weight-diameter relations of serviceberry twigs. J. Wildl. Manage. 34:456-460.

MacCracken, J.G. 1992. Ecology of moose on the Copper River Delta, Alaska. Ph.D. Thesis, Univ. Idaho, Moscow, Ida.

MacCracken, J.G., and L.A. Viereck. 1990. Browse regrowth and use by moose following fire in interior Alaska. Northwest Sci. 64:11-18.

Oldemeyer, J.L. 1982. Estimating production of paper birch and utilization by browsers. Can. J. Forest Res. 12:52-57.

Peek, J.M. 1970. Relation of canopy area and volume to production of three woody species. Ecology 51:1098-1101.

Peek, J.M., L.W. Krefting, and J.C. Tappeiner. 1971. Variation in twig diameter-weight relationships in northern Minnesota. J. Wildl. Manage. 35:501-507.

Provenza, F.D., and P.J. Urness. 1981. Diameter-length-weight relations for blackbrush (Coleogyne ramosissima) branches. J. Range Manage. 34:215-217.
Roundy, B.A., G.B. Ruyle, and J. Ard. 1989. Estimating production and utilization of jojoba. J. Range Manage. 42:75-78.

Rumble, M.A. 1987. Using twig diameters to estimate browse utilization in three shrub species on southeastern Montana. p. 172-175 In: F. B. Provenza, J.T. Flinders, and E.D. McArthur (compilers). Proc.-Symp. on Plant-Herbivore Interactions. USDA Forest Serv., Gen. Tech. Rep. INT-222.

Ruyle, J.E. Bowns, and A.F. Schlundt. 1983. Estimating snowberry (Symphoricarpos oreophilus) utilization by sheep from diameter-weight relations. J. Range Manage. 36:472-474.

Shafer, E.L. 1963. The twig count method for measuring hardwood deer browse. J. Wildl. Manage. 27:428-437.

Sprugle, D.G. 1983. Correcting for bias in log-transformed allometric equations. Ecology 64:209-210.

Snee, R.D. 1977. Validation of regression models: methods and examples. Technometrics 19:415-428.

Telfer, E.S. 1969. Twig-weight diameter relationships for browse species. I. Wildl. Manage. 33:917-921.

Thilenius, J.T. 1988. Weight distribution in the current annual twigs of Barclay willow. USDA, Forest Serv., Res. Note, PNW-RN-472.

Thilenius, J.T. 1990. Dimensional weights and forage of Barclay willow and sweetgale on moose ranges in the wetlands of the Copper River Delta, Alaska. Forest Ecol. Manage. 33/34:463-483.

Uresk, D.W., R.O. Gilbert, and W.H. Rickard. 1977. Sampling big sagebrush for phytomass. J. Range Manage. 30:311-314.

Viereck, L.A., C.T. Dyrness, and A.R. Batten. 1986. The 1986 revision of the Alaska vegetation classification. USDA, Forest Serv., Inst. N. Forest., Fairbanks, Alaska.

Yarie, J. and B.R. Mead. 1989. Biomass regression equations for determination of verticle structure of major understory species of southeast Alaska. Northwest Sci. 63:221-231. 